\title{
Study of Input Parameters of Layered Half-Space used for Soil Modelling
}

\author{
CAJKA RADIM, NEUWIRTHOVA ZDENKA (Z.N.) \\ Department of Structures \\ Faculty of Civil Engineering, VŠB - Technical University of Ostrava \\ CZECH REPUBLIC
}

\begin{abstract}
This article deals with a problem of soil modeling. That is a necessary part of foundation modeling. The soil modeling can directly influent the resulting deformation of the foundations and therefore deformation of the whole building. The accurate procedure that can simulate the foundation-soil interaction is still unknown. A greater understanding of the issue through experiments and numerical modeling is important for a good application and proper use in practice. To improve this understanding an experimental test of a concrete slab was performed on special testing equipment. The experiment is complemented by numerical modeling. Numerical models are created in the Ansys software. The article features three cube models and a half-sphere model. Deformations on all featured models are discussed and compared to the experimental values and simplified hand calculation. The subsoil model is based on the Boussinesq half-space theory. The soil section is assumed homogeneous and layered. The size of models is assumed as a changing parameter from $10 \mathrm{~m}$ to $30 \mathrm{~m}$. A recommended model size was evaluated from the parametric study as a match of deformation from models and the experiment. This computed model size is compared with an affected depth described by the standard ČSN 731001. Computation was performed using supercomputer Anselm in the National Supercomputing Center IT4Innovations in the VSB-Technical University of Ostrava.
\end{abstract}

Key-Words: - Ansys, Finite Element Method (FEM), HPC, Layered half-space, Soil modeling, Supercomputer.

Received: June 16, 2020. Revised: October 10, 2020. Accepted: October 21, 2020.

Published: November 1, 2020.

\section{Introduction}

A numerical model of soil-structure interaction is essential for the design of the whole building structure especially foundations. A key aspect of the soil-structure-interaction numerical model is the choice of material models that account for soil and foundation physically-nonlinear behavior that is caused by heterogeneous particles. Another important aspect of the soil-structure-interaction numerical model is the interaction itself because tensile forces cannot be transferred through the soil, and it also defines the stress transmission.

The soil behavior has a space-dependent strongly nonlinear character that is difficult to describe with the simplified plane theories [1]. The elastic halfspace or contact models are more suitable. An advanced constitutive model setting, that captures the real behavior, can be very complicated. Correctly determine the size of the 3D soil model, appropriate boundary conditions, and size of the finite element mesh are particularly problematic [2]. Research from Vaskova and Cajka was executed on a table computer and reached the limit of the model size. Therefore is limited by the size of the modeled area itself. Research proves that the deformation relies on the size of the subsoil, but the dependency is not clear. A further deformation is unsure and cannot be estimated. As a solution, this research is performed on the supercomputer Anselm as an extended parametric study. Several numerical modeling studies focus sub-parts on related phenomena like fiber orientation [3], punching of concrete elements [4], or structural failure [5]. But it is important to deal with it as a whole. And with their combination we expect restrictions by limited model size once again.

The use of a complex, advanced model usually requires fine finite element mesh and it is rather computationally-intensive. The capacity of the standard workstation is insufficient to demands on time calculation considering the requirements for a fast solution including larger tasks. A possible solution for this problem is the use of parallel computer code calculations that divide calculations 
to multiple cores. Parallel computation is done through special procedures [6]. Larger structures are usually analyzed with the use of the larger computer (the supercomputer) [3]. They are also useful for solving models with fine meshes, i.e. a large number of unknowns, for the nonlinear model, or more advanced contact model. The use of the supercomputers is beneficial in other areas of civil engineering to perform composition visualization in the urban landscape [7], the layout of the house in the historic city [8], or parametric modeling in architecture [9].

The optimal procedure to provide sufficiently accurate results that work under all circumstances has not been accomplished yet. That's why scientists deep the theoretical basis of the research field by performing experimental tests [10], [11] together with the development of theoretical and numerical computational models [5], [12], [13] to better describe and understand the real behavior.

The experimental tests focus on the soil deformations trough the concrete slab [10], [12], slab punching [14], [15], [4], the tension inside of the soil [16] and soil stiffness under the slab [17]. Not only the concrete slab but also fiber-reinforced concrete or steel fiber concrete was examined. Some of the more common problems include the behavior of elements from fiber-reinforced concrete [18] or steel fiber concrete for pavement [19]. This article should extend our knowledge in a way of how the selected model and inputs can affect the numerical results and dependence on the selected model size. And contribute to the creation of optimized models as well as using supercomputers into civil engineering practice.

\section{Methods}

\subsection{Experimental testing}

The basic experiment method was designed to examine the behavior of the concrete slab on the subsoil. The special testing equipment (Figure 1,2) named Stand was constructed at the Faculty of Civil Engineering at VŠB - Technical University of Ostrava [11] for this purpose. Sets of experimental tests were performed here [12], [2], [13].

The testing equipment [11] consists of steel construction anchored by micro piles to the subsoil. The hydraulic press is placed between the tested slab and the steel construction to apply the vertical load to the slab. The slab has been located in the center of the testing area so that the results are not affected by uneven ground settlement due to eccentric placement between the foundation strips.

The first test's purpose was to try and prove the proper function of the device. After this, a series of tests on concrete slabs were performed. The tests were performed on slabs with standard dimensions $2000 \times 2000 \times 150 \mathrm{~mm}$ and all slabs in one set were placed on the same subsoil with the same parameters. The main difference was in the method of concrete reinforcing. All slabs were loaded with force up to $1000 \mathrm{kN}$, which is the device limit, or until the bearing capacity of the slab was reached.

\subsection{Numerical modelling}

Numerical models are developed based on the experiments. This enables direct verification of the results and numerical model itself. Similar numerical models were solved on a standard workstation before [2] but the capacity of the standard workstation was insufficient for the research, therefore a supercomputer was used. The paper explores the possibilities of the supercomputer and its application to the solved problems. Several different numerical models were made and solved by Ansys Multiphysics HPC and ANSYS Workbench. A numerical model was prepared in the Ansys macro code which was launched on the supercomputer Anselm located in the National Supercomputing Center IT4Innovations VSBTechnical University of Ostrava.

\section{Experiment results}

Slab no. D10-G01 (Figure 1) from the series was selected as a reference for this paper. The slab was made of plain concrete with no reinforcements of concrete compressive strength class C 25/30 (Figure 2). Together with the slab, few test samples were produced from the same mixture and tested in the laboratory. Following characteristics were evaluated from laboratory tests:

- average compressive strength of concrete (cube test) f_(c,cube) $=25.11 \mathrm{MPa}$

- average compressive strength of concrete (cylinder test) f_(c,cyl) $=20.03 \mathrm{MPa}$

- average tensile strength $\mathrm{f} \_t=2.10 \mathrm{MPa}$

- average elastic modulus E $=19750 \mathrm{MPa}$ 


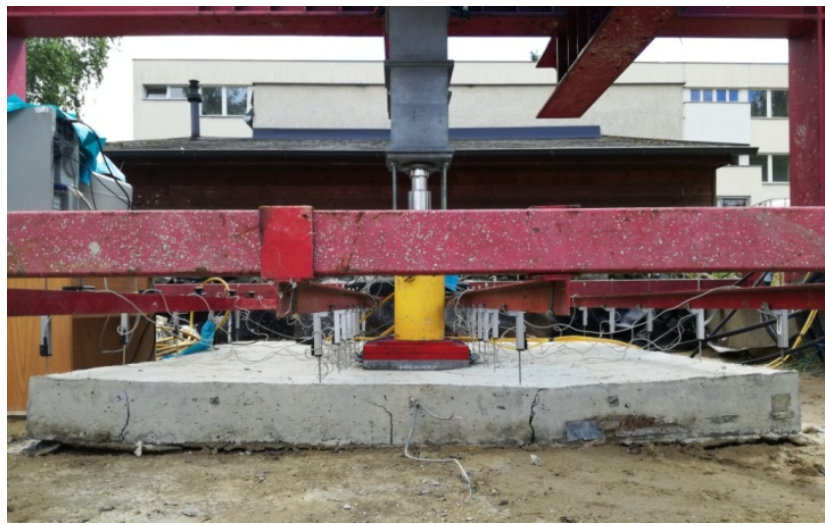

Fig. 1 - (Typical concrete slab with dimensions 2 x 2 m during testing. Author: Z.N.

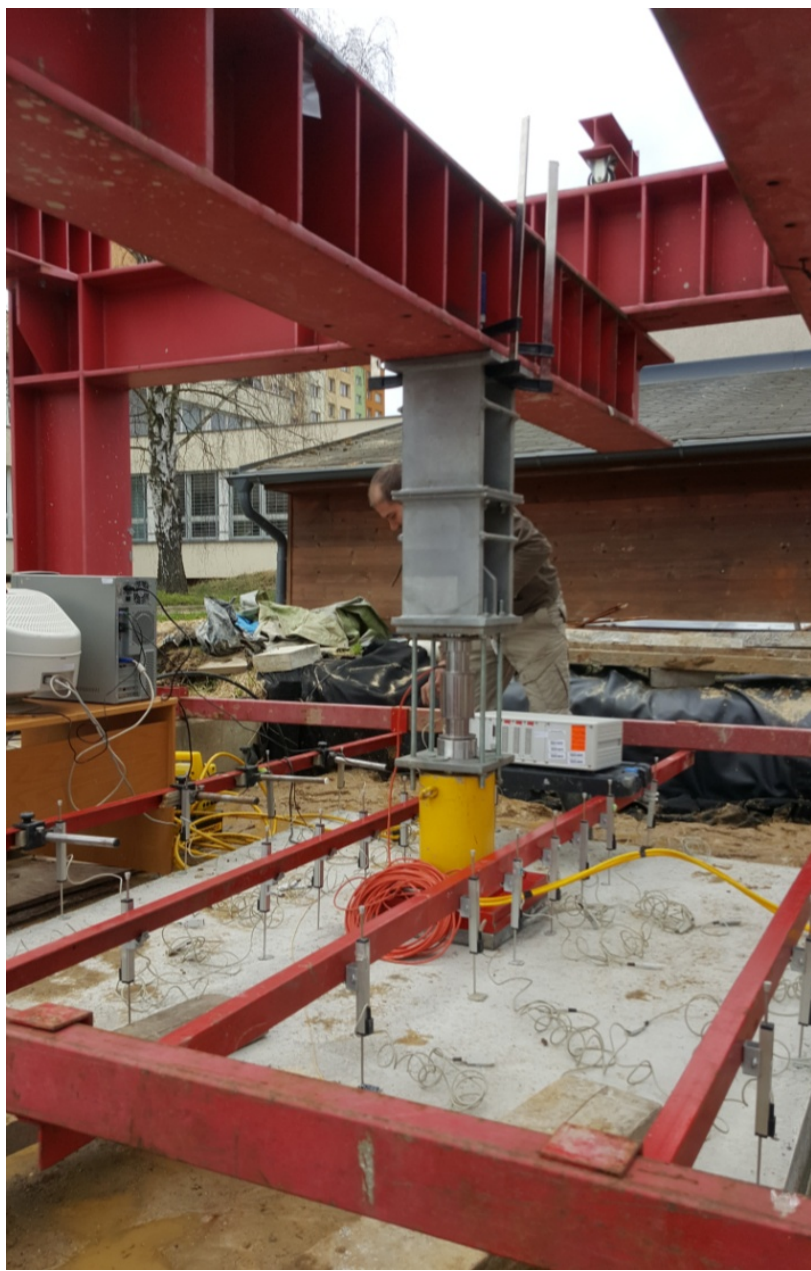

Fig. 2 - Photo of the testing device. Author: Z.N.

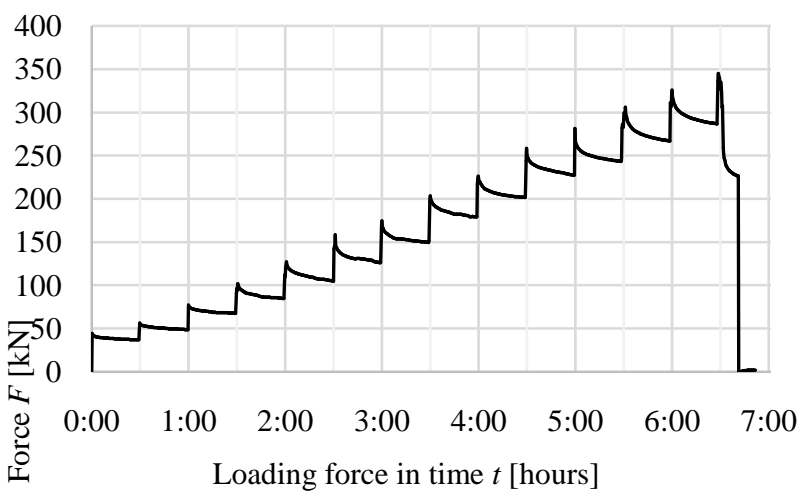

Fig. 3 - Loading force in time. Author: Z.N.

The slab was loaded by steps (Figure 3) with increment by $25 \mathrm{kN}$ every half hour to allow soil creep a bit as it would in real conditions. The maximal loading force was $345 \mathrm{kN}$ then the maximum bearing capacity of the slab was reached. Deformation of the slab was tracked by tensometers (Figure 2). Results of the experiment were published in detail [20] and the maximum deformation approximated from measured data is $21.68 \mathrm{~mm}$ in the center under the load location.

The modulus of elasticity of soil was measured by static load test before the experiment. The slab was tested right after the change of the subsoil; therefore, the soil was loaded for the first time. For this reason, $E_{\operatorname{def} 1}$ was selected in numerical models. Measured values from the static load test at the surface were:

- First loading cycle $E_{\text {def } 1}=6.8 \mathrm{MPa}$;

- Second loading cycle $E_{\text {def } 2}=12.5 \mathrm{MPa}$.

$$
-\frac{E_{\text {def } 2}}{E_{\text {def } 1}}=1,83
$$

\section{Numerical models}

The numerical model was created based on the elastic half-space theory. A solid homogeneous model based on the Boussinesq's method for stress distribution under the vertical concentrated load was already assumed in the previous paper of authors in a small scale [21]. This approach was confirmed and therefore, the layered half-space was used also here. The assumptions of the Boussinesq theory are:

- the soil mass is:

- elastic

- isotropic

- homogeneous

- semi-infinite

- weightless 
- the applied load is vertical, concentrated acting on the surface

- the Hook's Low is applied, that means that the ratio between stress and strain is constant

The shape of the soil model was selected as a cube/block with finite dimensions and as a halfsphere with finite dimensions. The cube soil model has a homogenous material model that has the same elastic modulus trough full volume. In a addition, a layered model of the cube was selected. In this case the cube is divided into layers with increasing elastic modulus with depth. The increasing elastic modulus expresses the increasing stiffness of the soil with depth.

\subsection{Cube soil model}

Solid 45 was used for three-dimensional models [22]. The element Solid 45 is defined by 8 nodes with three degrees of freedom at each node (translation in the $x, y$, and $z$-direction). The finite element size is $0.2 \mathrm{~m}$ for every model to eliminate inaccuracies due to the size of the finite elements.

The behavior of the soil model is characterized by the Modulus of Elasticity and Poisson Coefficient. The self - weight was neglected based on Boussinesq's assumptions.

Input characteristics:

- Modulus of elasticity $E_{\text {def } 1}=6.8 \mathrm{MPa}$;

- Poisson coefficient $\mu=0.35$;

- Pressure $87500 \mathrm{~Pa}$ on $2 \times 2 \mathrm{~m}^{2}$ area. Applied pressure corresponds to the maximum loading force at a maximum bearing capacity of the slab before failure which was $345 \mathrm{kN}$ rounded to $350 \mathrm{kN}$ and converted to surface load $2 \times 2$ $\mathrm{m}^{2}$ which matches the slab dimensions.

Material model:

a) Homogeneous soil model - the whole cube soil model has the same soil characteristics.

b) Layered soil model - the cube is divided into layers with different characteristics. The thickness of the layers is $0.2 \mathrm{~m}$ and the Elasticity modulus is increasing by relationship (1) and (2) by Feda \& Bazant [23]. The elasticity modulus is itemized in Table 1 . The increment is described by the cubic equation (Figure 4 ).

$$
\begin{gathered}
E_{d e f z}=E_{0} \cdot\left(p_{z}+d_{0}\right)^{m} \\
m=\frac{1}{\mu}-2
\end{gathered}
$$

Table 1 - Development of the modulus of elasticity in dependence on the depth of the subsoil.

\begin{tabular}{llll}
\hline Depth lz [m] & $\boldsymbol{E}_{\boldsymbol{d e f z}}$ [MPa] & Depth lz [m] & $\boldsymbol{E}_{\boldsymbol{d e f z}}[\mathrm{MPa}]$ \\
\hline 0 & 06.80 & 12 & 61.28 \\
2 & 17.44 & 14 & 69.28 \\
4 & 27.02 & 16 & 77.12 \\
6 & 36.05 & 18 & 84.84 \\
8 & 44.71 & 20 & 92.44 \\
10 & 53.10 & 22 & 99.93 \\
\hline
\end{tabular}

There is no way how to identify the size of the numerical model. Therefore, a parametric study was created considering three variants of the width-depth ratio. In the first variant, the width of the soil was selected firmly to $10 \mathrm{~m}$ (in the axis $x$ and $y$ ) and the height of soil $l_{z}$ (in the axis $z$ ) was defined variable, starting at depth $2 \mathrm{~m}$ with $2 \mathrm{~m}$ increment in each step and maximum at $30 \mathrm{~m}$. In the second variant the depth of the soil was selected firmly to $10 \mathrm{~m}$ and the width of the soil in both directions $l_{x}=l_{y}$ was defined variable with $2 \mathrm{~m}$ increment. Once again, third model was constructed starting at a width of 2 $\mathrm{m}$ with $2 \mathrm{~m}$ increment at each step and maximum at $30 \mathrm{~m}$. And the last variant was set the same in all three directions increasing from $2 \mathrm{~m}$ by $2 \mathrm{~m}$ increment in each step up to $30 \mathrm{~m}$. The parametric study monitor the changes in the results based on the size of the area and boundary conditions.

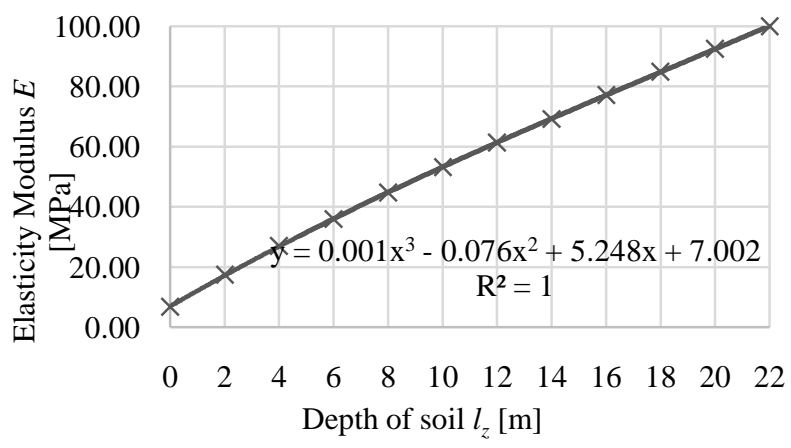

Fig. 4 - Elasticity modulus dependent on depth. Author: Z.N.
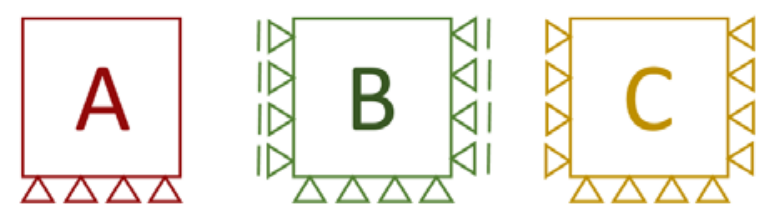

Fig. 5 - Assumed boundary conditions. Author: Z.N.

Three types of boundary conditions were considered. All three models are pinned on the bottom surface. The difference is how the sides of the soil are supported. In the first type A, the bulge 
of the soil is allowed. In the second variant the vertical displacement is allowed and in $\mathrm{C}$ are sides pinned at their exact positions as shown in Figure 5. The prepared typical model can be found in Figure 6 and its solution in Figure 7.

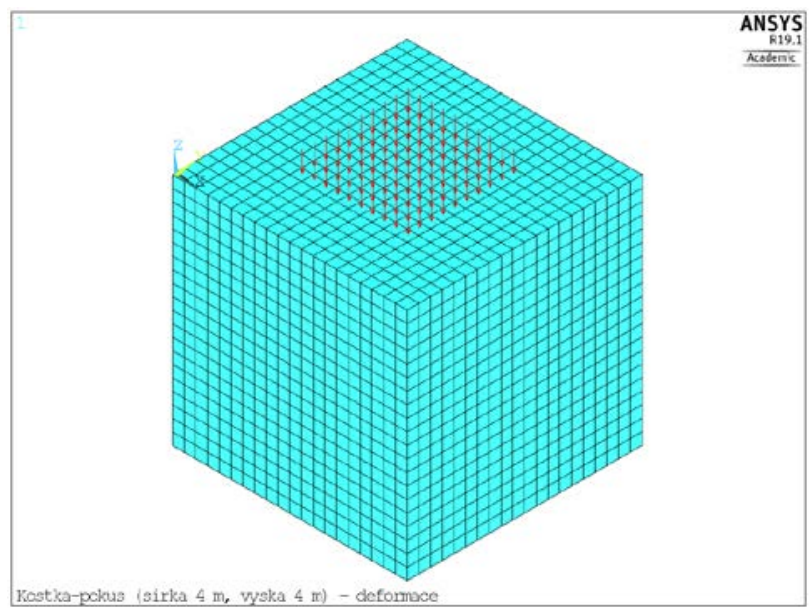

Fig. 6 - Typical numerical model layout. Cube with dimensions of $4 \times 4 \times 4 \mathrm{~m}$ with finite element size $0.2 \mathrm{~m}$ - mesh and pressure location. Author: Z.N.

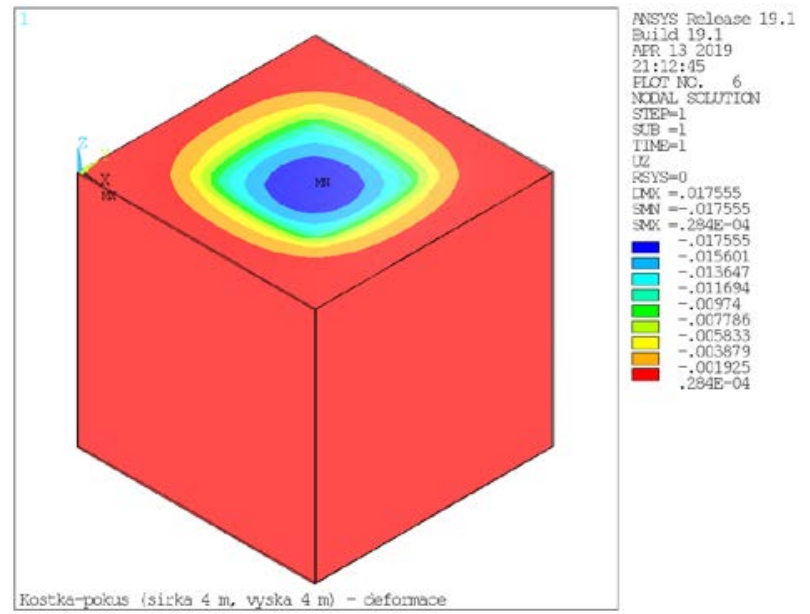

Fig. 7 - Typical numerical model layout. Cube with dimensions of $4 \times 4 \times 4 \mathrm{~m}$ with finite element size $0.2 \mathrm{~m}$ - graphical description of deformation. Author: Z.N.

\subsection{Half-sphere soil model}

The half-sphere model is also based on the Boussinesq theory and was modeled as homogeneous isotropic linear elastic. The model consists of the soil and the concrete slab. The slab and the subsoil are connected by the frictional contact to exclude the tensional stress from the interaction (Figure 10). The boundary conditions are pinned through the whole curved area (Figure 8).

Model characteristics:

- Modulus of elasticity (soil): $E_{\text {def1 }}=6.8 \mathrm{MPa}$;
- Poisson coefficient (soil): $\mu=0.35$;

- Modulus of elasticity (concrete): $E_{c}=19.5$ GPa;

- Poisson coefficient (concrete): $\mu_{c}=0.3$;

- Force: $F=350 \mathrm{kN}$ applied through $0.4 \mathrm{~m} \times$ $0.4 \mathrm{~m}$ (Figure $6 \mathrm{~b}$ ) area.

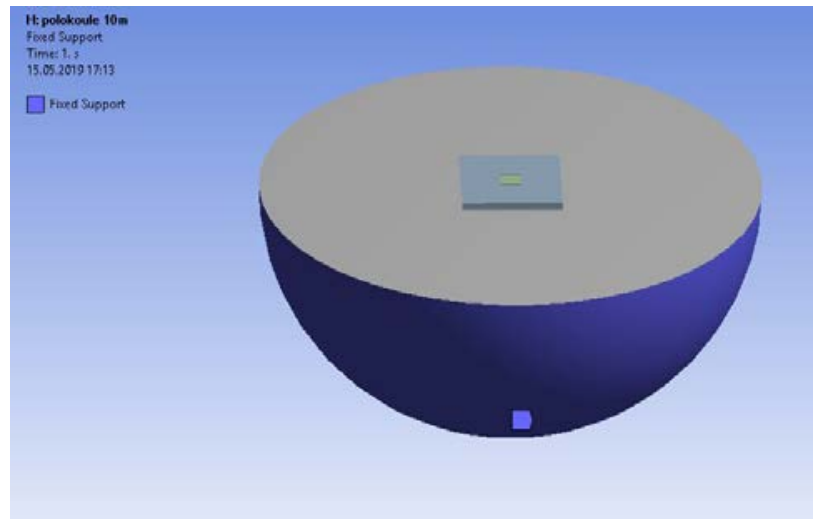

Fig. 8 - Model of half-sphere soil model - boundary conditions. Author: Z.N.

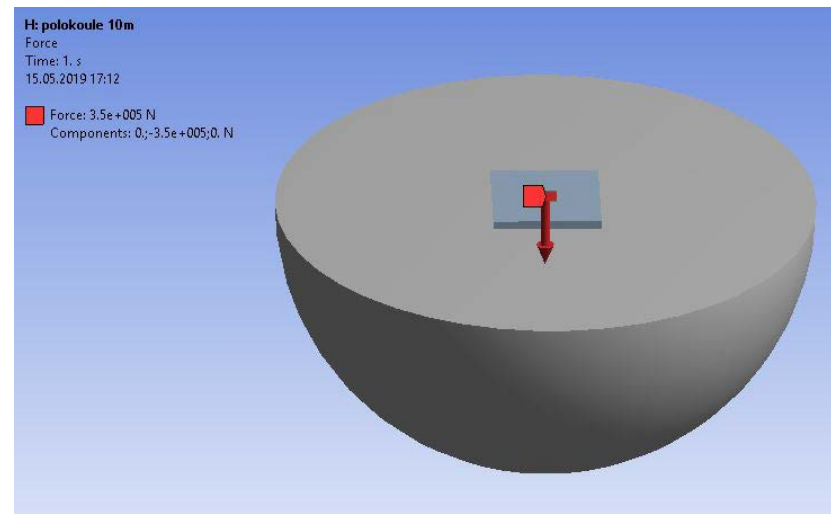

Fig. 9 - Model of half-sphere soil model - applied force. Author: Z.N.

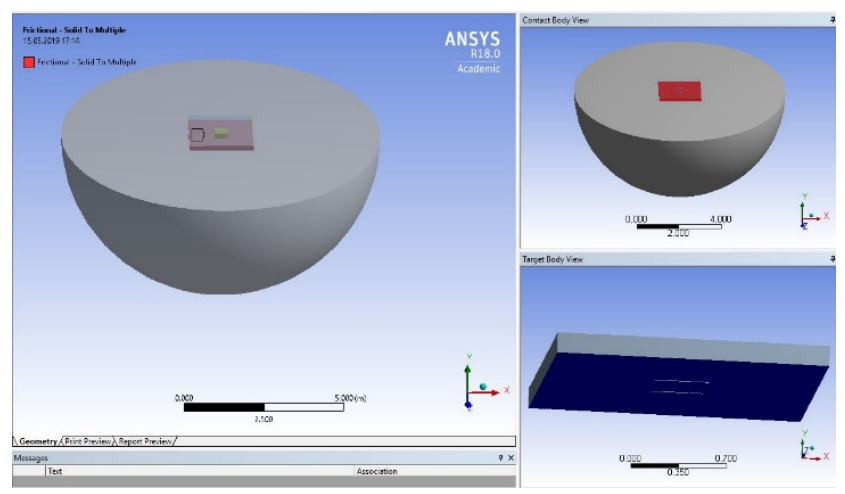

Fig. 10 - Half-hemisphere model - contact and target elements. Author: Z.N. 


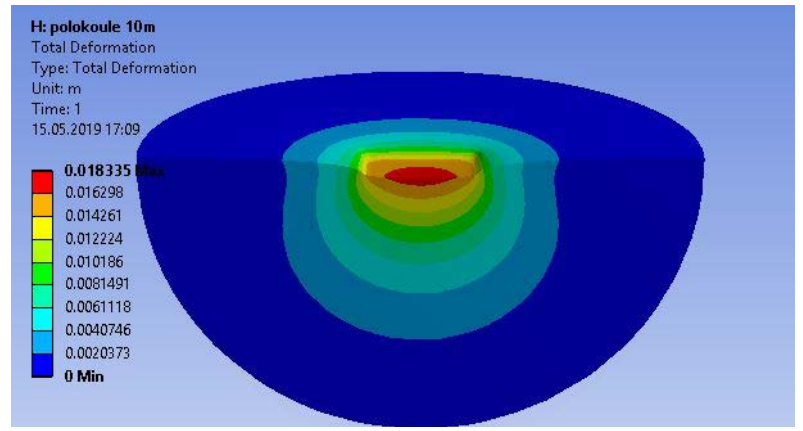

Fig. 11 - Half-hemisphere model - graphical solution, deformation in the center cross-section. Author: Z.N.

\subsection{Hand calculation of elastic deformation}

Simplified hand calculation was performed to receive tentative calculation and prove FEM results. The hand calculation result gives maximum possible deformation. This deformation will not be achieved in any other way. The hand calculation of deformation $w$ is calculated based on elastic compression according to Hooks law neglecting the influence of the surrounding soil. The platform size of the segment is $2 \times 2 \mathrm{~m}$ based on slab size (Figure 12, hand calculation). Only simplified boundary conditions on the bottom are set. This way the system is statically determinate and can be computed by hand. The same task was computed by FEM using the same geometry and boundary conditions as a reference. Deformation $w$ is computed according to mathematical formula (3) with input parameters:

$$
\begin{gathered}
\text { - } \text { modulus of elasticity } E_{\text {def }}=6.8 \mathrm{MPa} \\
\text { - } \text { pressure area } A=2 \times 2 \mathrm{~m}^{2} \\
\text { - } \quad \text { force } F=350 \mathrm{kN} \\
\text { - } \quad \text { depth } l_{z} \text { is variable } \\
\quad w=\frac{F}{E \cdot A} \cdot l_{z}
\end{gathered}
$$

Calculation results are linear and dependent on the selected depth. When depth $l_{z}=0$ then deformation $w=0$. In the case when the depth $l_{z}=\infty$ also the deformation $=\infty$.

\section{Results}

A set of models were made and compared to fulfill set goals. Ten sets of models with different geometry (Figure 12) and boundary conditions were computed.
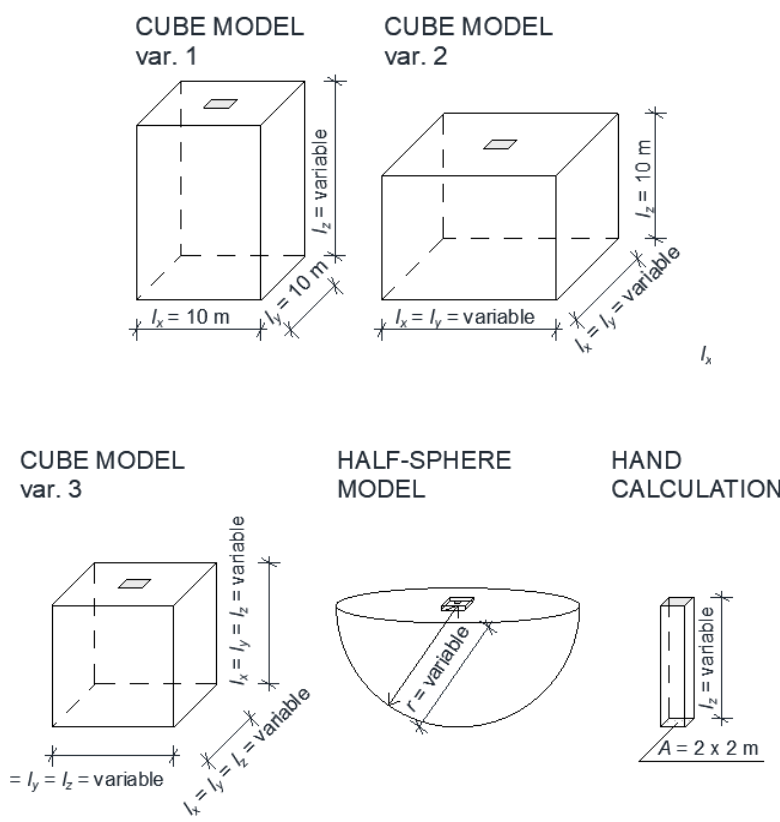

Fig. 12 - Defined parameters and geometry of tasks by the type of task: Cube soil model with a fixed width of the cube; Cube soil model with fixed depth; Cube soil model with both width and depth variable; half-sphere soil model; simplified hand calculation. Author: Z.N.

The prepared models were computed (Figure 12) and results were evaluated into tables. Graphs were created based on the results. The results of layered cube models are in Table 2, Table 3, and Table 4. The half-sphere model and hand calculation results are in Table 5. The results from homogeneous cube models are in Table 6, Table 7, and Table 8. Three graphs summarize and compare results (Figure 13, Figure 14, and Figure 15). The computed results are compared with the experimental value.

In the second part of the tables, the strain displacement increment per depth increment was computed based on the relation (4). This allows observing the slope of the curve and its angle.

$$
\Delta \varepsilon_{i}=\frac{\Delta w}{\Delta h}=\frac{w_{i}-w_{i-1}}{h_{i}-h_{i-1}}
$$

The layered model with variable height and platform of $10 \times 10 \mathrm{~m}$ (Table 2) were evaluated first. The results are approximately the same in the depth $2 \mathrm{~m}$ for all three boundary conditions but with the increasing depth, they start to differ. This phenomenon is caused by the boundary conditions itself. The boundary conditions on the sides of the cube are not activated in the small depth so the only variable influencing the results is the height of the subsoil. Once the depth increases the influence of the boundary conditions on the sides become 
activated. It is most noticeable on the $\mathrm{C}$ boundary condition, after depth reaching $16 \mathrm{~m}$ there is no additional deformation because it is prevented by pinned edges. The displacement increment per depth increment of boundary type $\mathrm{A}$ is larger than the type $B$ because the soil is bulging to the sides. The overall displacement increment per depth increment behavior of all three boundary conditions is similar. It is very steep at a small height but it stabilizes in a few steps and after this it is constant.

Table 2. Cube model, layered, variant 1: Surface deformation $w$ for different height of the cube $l_{z}$ for the cube with width $l_{x}=l_{y}=10$ meters

\begin{tabular}{ccccccc}
\hline $\begin{array}{c}\text { Height } \boldsymbol{I}_{\mathbf{z}}[\mathbf{m}] \\
\text { Boundary } \\
\text { condition } \\
\text { type }\end{array}$ & \multicolumn{2}{c}{ Deformation $\boldsymbol{w}[\mathrm{mm}]$} & \multicolumn{5}{c}{ Strain $\Delta \boldsymbol{\varepsilon}[-]$} \\
\hline 2 & -15.80 & -15.77 & -15.77 & - & - & - \\
4 & -20.46 & -20.16 & -20.13 & -2.333 & -2.198 & -2.181 \\
6 & -22.51 & -21.56 & -21.49 & -1.025 & -0.700 & -0.680 \\
8 & -23.89 & -22.33 & -22.00 & -0.689 & -0.381 & -0.258 \\
10 & -25.04 & -22.98 & -22.20 & -0.578 & -0.329 & -0.101 \\
12 & -26.12 & -23.63 & -22.28 & -0.538 & -0.322 & -0.040 \\
14 & -27.17 & -24.27 & -22.31 & -0.523 & -0.321 & -0.015 \\
16 & -28.20 & -24.91 & -22.33 & -0.517 & -0.321 & -0.006 \\
18 & -29.23 & -25.55 & -22.33 & -0.515 & -0.321 & -0.002 \\
20 & -30.26 & -26.19 & -22.33 & -0.515 & -0.321 & -0.001 \\
22 & -31.29 & -26.83 & -22.33 & -0.515 & -0.321 & 0.000 \\
\hline
\end{tabular}

Table 3. Cube model, layered, variant 2: Surface deformation $w$ for different width of the cube $l_{x}=l_{y}$ with height 10 meters.

\begin{tabular}{ccccccc}
\hline $\begin{array}{c}\mathbf{l} \mathbf{x}=\mathbf{l y}[\mathbf{m}] \\
\text { Boundary } \\
\text { condition } \\
\text { type }\end{array}$ & \multicolumn{2}{c}{ Deformation $\mathbf{w}[\mathrm{mm}]$} & \multicolumn{4}{c}{ Strain $\Delta \boldsymbol{\varepsilon}[-]$} \\
\hline 2 & -127.53 & -80.18 & -11.20 & - & - & - \\
4 & -44.17 & -31.72 & -17.83 & 41.680 & 24.227 & -3.314 \\
6 & -30.70 & -25.03 & -20.31 & 6.735 & 3.348 & -1.241 \\
8 & -26.65 & -23.41 & -21.53 & 2.024 & 0.809 & -0.609 \\
10 & -25.04 & -22.98 & -22.20 & 0.801 & 0.212 & -0.338 \\
12 & -24.30 & -22.92 & -22.60 & 0.373 & 0.032 & -0.198 \\
14 & -23.91 & -22.97 & -22.84 & 0.194 & -0.025 & -0.120 \\
16 & -23.69 & -23.05 & -22.99 & 0.110 & -0.038 & -0.075 \\
18 & -23.56 & -23.12 & -23.09 & 0.067 & -0.035 & -0.048 \\
20 & -23.47 & -23.17 & -23.15 & 0.042 & -0.028 & -0.032 \\
22 & -23.42 & -23.21 & -23.19 & 0.028 & -0.020 & -0.022 \\
\hline & & & & & & \\
\hline
\end{tabular}

Table 4 - Cube model, layered, variant 3: Surface deformation $\mathrm{w}$ for cube model with $l_{x}=l_{y}=l_{z}$.

Parameter

[m]

Strain $\Delta \varepsilon[-]$

\begin{tabular}{ccccccc}
$\begin{array}{c}\text { Boundary } \\
\text { condition } \\
\text { type }\end{array}$ & A & B & C & A & B & C \\
\hline 2 & -24.43 & -16.04 & -10.92 & - & - & - \\
4 & -24.72 & -19.69 & -17.55 & -0.147 & -1.828 & -3.316 \\
6 & -24.87 & -21.46 & -20.12 & -0.073 & -0.884 & -1.281 \\
8 & -24.97 & -22.40 & -21.42 & -0.052 & -0.472 & -0.651 \\
10 & -25.04 & -22.98 & -22.20 & -0.035 & -0.290 & -0.393 \\
12 & -25.09 & -23.37 & -22.73 & -0.025 & -0.196 & -0.263 \\
14 & -25.13 & -23.66 & -23.11 & -0.018 & -0.141 & -0.188 \\
16 & -25.16 & -23.87 & -23.39 & -0.014 & -0.106 & -0.141 \\
18 & -25.18 & -24.03 & -23.61 & -0.011 & -0.083 & -0.110 \\
20 & -25.20 & -24.17 & -23.78 & -0.009 & -0.066 & -0.088 \\
22 & -25.21 & -24.27 & -23.93 & -0.007 & -0.054 & -0.072 \\
\hline
\end{tabular}

Next, the layered cube model with a set height and increasing platform was observed (Table 3). In contrast to Table 2, the results in Table 3 differ most in the smallest width and then become comparable with the increasing width of the model. This is caused by the boundary conditions behavior which is enhanced by the small platform dimensions in proportion to the height. This is visible in the example with boundary condition A and layout of 2 x $2 \mathrm{~m}$. There is no side boundary condition so this case is very similar to the hand calculation. Therefore, this final deformation depends only on the area multiplied by the modulus of elasticity. In contrast to boundary condition C, size $2 \times 2 \mathrm{~m}$, where the deformation is limited by the deflection basin between pinned ends. This phenomenon becomes less visible with a width of 10 meters and above.

Table 5 - Half-sphere model, Hand calculation: Deformation $w$ using numerical solution

\begin{tabular}{|c|c|c|c|c|c|c|}
\hline \multirow[b]{2}{*}{$\begin{array}{c}\text { Parame } \\
\text { ter } h \\
{[\mathrm{~m}]}\end{array}$} & \multicolumn{3}{|c|}{ Deformation $w$ [mm] } & \multicolumn{3}{|c|}{ Strain $\Delta \varepsilon$ [-] } \\
\hline & $\begin{array}{c}\text { Linear } \\
\text { half- } \\
\text { sphere }\end{array}$ & $\begin{array}{c}\text { Hand } \\
\text { calculat } \\
\text { ion }\end{array}$ & $\begin{array}{c}\text { Hand } \\
\text { calculat } \\
\text { ion by } \\
\text { FEM }\end{array}$ & $\begin{array}{c}\text { Linear } \\
\text { half- } \\
\text { sphere }\end{array}$ & $\begin{array}{c}\text { Hand } \\
\text { calculat } \\
\text { ion }\end{array}$ & $\begin{array}{c}\text { Hand } \\
\text { calculat } \\
\text { ion by } \\
\text { FEM }\end{array}$ \\
\hline 2 & -14.07 & -25.74 & -25.020 & - & - & \\
\hline 4 & -18.67 & -51.47 & -50.915 & -2.301 & -12.868 & -12.947 \\
\hline 6 & -20.73 & -77.21 & -76.649 & -1.028 & -12.868 & -12.867 \\
\hline 8 & -21.50 & -102.94 & -102.38 & -0.383 & -12.868 & -12.868 \\
\hline 10 & -22.38 & -128.68 & -128.12 & -0.244 & -12.868 & -12.868 \\
\hline 12 & -22.71 & -154.41 & -153.85 & -0.164 & -12.868 & -12.868 \\
\hline 14 & -23.05 & -180.15 & -179.59 & -0.167 & -12.868 & -12.868 \\
\hline 16 & -23.16 & -205.88 & -205.32 & -0.149 & -12.868 & -12.868 \\
\hline 18 & -23.38 & -231.62 & -231.06 & -0.110 & -12.868 & -12.868 \\
\hline 20 & -23.51 & -257.35 & -256.79 & -0.064 & -12.868 & -12.868 \\
\hline 22 & -23.68 & -283.09 & -282.53 & -0.085 & -12.868 & -12.868 \\
\hline
\end{tabular}


Table 6 - Cube model, homogeneous, variant 1: Surface deformation $\mathrm{w}$ for different height of the cube lz for cube with width $l_{x}=l_{y}=10$ meters

\begin{tabular}{ccccccc}
\hline $\begin{array}{c}\boldsymbol{I}_{\boldsymbol{x}}=\boldsymbol{I}_{\boldsymbol{y}}[\mathbf{m}] \\
\text { Boundary } \\
\text { condition } \\
\text { type }\end{array}$ & \multicolumn{3}{c}{ Deformation $\boldsymbol{w}[\mathbf{m m}]$} & \multicolumn{5}{c}{ Strain $\Delta \boldsymbol{\varepsilon}[-]$} \\
\hline 2 & -17.59 & -17.58 & -17.58 & - & - & - \\
4 & -22.16 & -22.04 & -22.03 & -2.288 & -2.226 & -2.221 \\
6 & -24.10 & -23.58 & -23.40 & -0.970 & -0.771 & -0.689 \\
8 & -25.42 & -24.54 & -23.86 & -0.658 & -0.482 & -0.231 \\
10 & -26.55 & -25.41 & -24.02 & -0.565 & -0.436 & -0.077 \\
12 & -27.61 & -26.27 & -24.07 & -0.533 & -0.430 & -0.025 \\
14 & -28.66 & -27.13 & -24.08 & -0.521 & -0.429 & -0.008 \\
16 & -29.69 & -27.99 & -24.09 & -0.517 & -0.429 & -0.003 \\
18 & -30.72 & -28.85 & -24.09 & -0.515 & -0.429 & -0.001 \\
20 & -31.75 & -29.70 & -24.09 & -0.515 & -0.429 & 0.000 \\
22 & -32.78 & -30.56 & -24.09 & -0.515 & -0.429 & 0.000 \\
\hline
\end{tabular}

Table 4 combines both previous concepts and includes results for variable width and height. From the results, we can observe a combination of both described phenomena but they are not so visible because they disturb and influence each other. For these reasons, the difference in results across boundary conditions in cube $2 \times 2 \times 2$ is bigger than in Table 2 but smaller than in Table 3 . The results from variant A width $2 \times 2$ meters can be described as uniaxial deflection behavior.

Table 5 summarizes the half-sphere model and hand calculations. The half-sphere results increase significantly until reaching a radius of 12 meters, then it's more uniform. The hand calculation increases linearly as expected.

The linear cube models (Table 6, Table 7, and Table 8) perform the same phenomenon when talking influence of boundary conditions and models as discussed before at the layered cube models. The phenomenon might be clearer to observe here. For all calculations, the results of the layered half-space are lower compared to the linear elastic half-space solution.

Table 7 - Cube model, homogeneous, variant 2: Surface deformation $w$ for different width of the cube $l_{x}=l_{y}$ with height 10 meters

\begin{tabular}{cccccccc}
\hline $\begin{array}{c}\boldsymbol{I}_{\boldsymbol{x}}=\boldsymbol{I}_{\boldsymbol{y}}[\mathrm{m}] \\
\text { Boundary } \\
\text { condition } \\
\text { type }\end{array}$ & A & B & C & A & B & C \\
\hline 2 & -128.12 & -107.23 & -12.57 & - & - & - \\
4 & -45.31 & -39.28 & -19.59 & 41.405 & 33.976 & -3.506
\end{tabular}

\begin{tabular}{ccccccc}
6 & -32.03 & -29.13 & -22.09 & 6.641 & 5.075 & -1.249 \\
8 & -28.08 & -26.35 & -23.32 & 1.975 & 1.389 & -0.616 \\
10 & -26.55 & -25.41 & -24.02 & 0.767 & 0.469 & -0.349 \\
12 & -25.86 & -25.08 & -24.43 & 0.346 & 0.165 & -0.208 \\
14 & -25.51 & -24.98 & -24.68 & 0.172 & 0.050 & -0.125 \\
16 & -25.33 & -24.97 & -24.83 & 0.092 & 0.007 & -0.075 \\
18 & -25.22 & -24.98 & -24.92 & 0.053 & -0.007 & -0.045 \\
20 & -25.16 & -25.00 & -24.98 & 0.031 & -0.010 & -0.027 \\
22 & -25.12 & -25.02 & -25.01 & 0.019 & -0.009 & -0.016 \\
\hline
\end{tabular}

Table 8 - Cube model, homogeneous, variant 3:

Surface deformation $w$ for cube model with $l_{x}=l_{y}$ $=l_{\mathrm{z}}$.

\begin{tabular}{|c|c|c|c|c|c|c|}
\hline \multirow{2}{*}{$\begin{array}{c}\text { Parameter } h \\
{[\mathrm{~m}]} \\
\text { Boundary } \\
\text { condition } \\
\text { type } \\
\end{array}$} & \multicolumn{3}{|c|}{ Deformation $w[\mathrm{~mm}]$} & \multicolumn{3}{|c|}{ Strain $\Delta \varepsilon[-]$} \\
\hline & A & B & C & A & B & C \\
\hline 2 & -25.06 & -21.45 & -12.42 & - & - & - \\
\hline 4 & -25.90 & -23.19 & -19.43 & -0.420 & -0.873 & -3.504 \\
\hline 6 & -26.23 & -24.36 & -21.97 & -0.164 & -0.584 & -1.270 \\
\hline 8 & -26.42 & -25.01 & -23.25 & -0.098 & -0.324 & -0.639 \\
\hline 10 & -26.55 & -25.41 & -24.02 & -0.063 & -0.202 & -0.384 \\
\hline 12 & -26.63 & -25.69 & -24.53 & -0.044 & -0.137 & -0.256 \\
\hline 14 & -26.70 & -25.88 & -24.90 & -0.032 & -0.099 & -0.183 \\
\hline 16 & -26.75 & -26.03 & -25.17 & -0.024 & -0.075 & -0.137 \\
\hline 18 & -26.78 & -26.15 & -25.38 & -0.019 & -0.058 & -0.107 \\
\hline 20 & -26.81 & -26.24 & -25.55 & -0.015 & -0.047 & -0.085 \\
\hline 22 & -26.84 & -26.32 & -25.69 & -0.012 & -0.038 & -0.070 \\
\hline
\end{tabular}

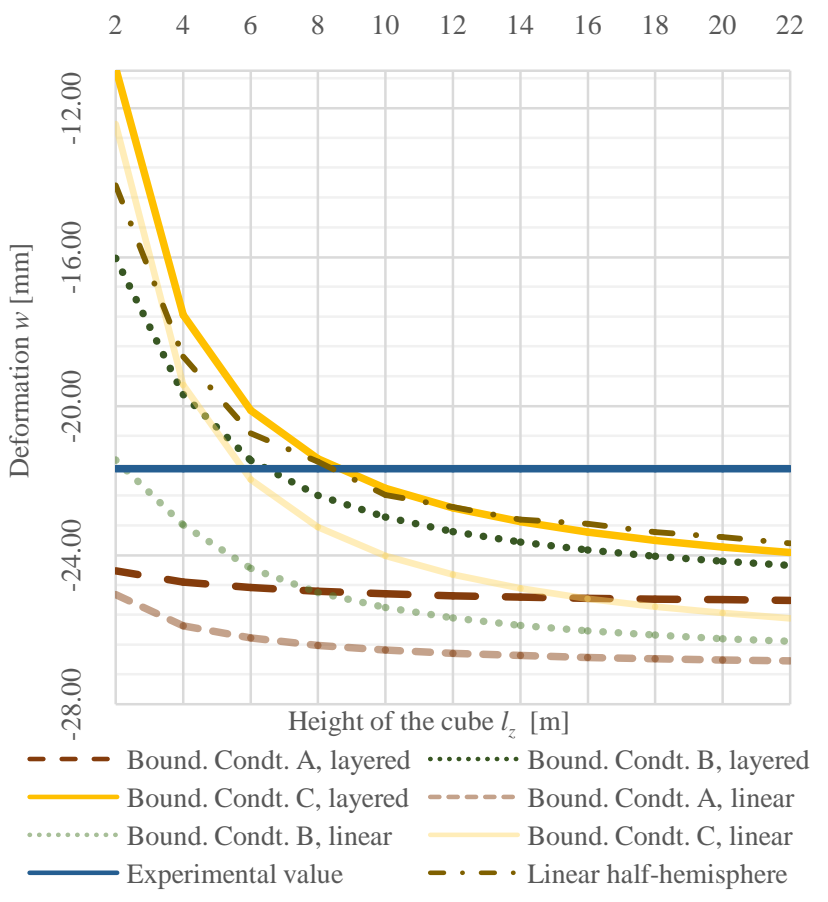


Fig. 13 - Surface deformation $w$ for layered cube model variant 1 (homogeneous and layered) with different height of the cube $l_{z}$ for the cube with width $l_{x}=l_{y}=10$ meters from Table II in all three boundary conditions, cube model variant 1 linear variation in all three boundary conditions (Figure 12), linear half-sphere from Table 5 and experimentally measured deformation. Author: Z.N.

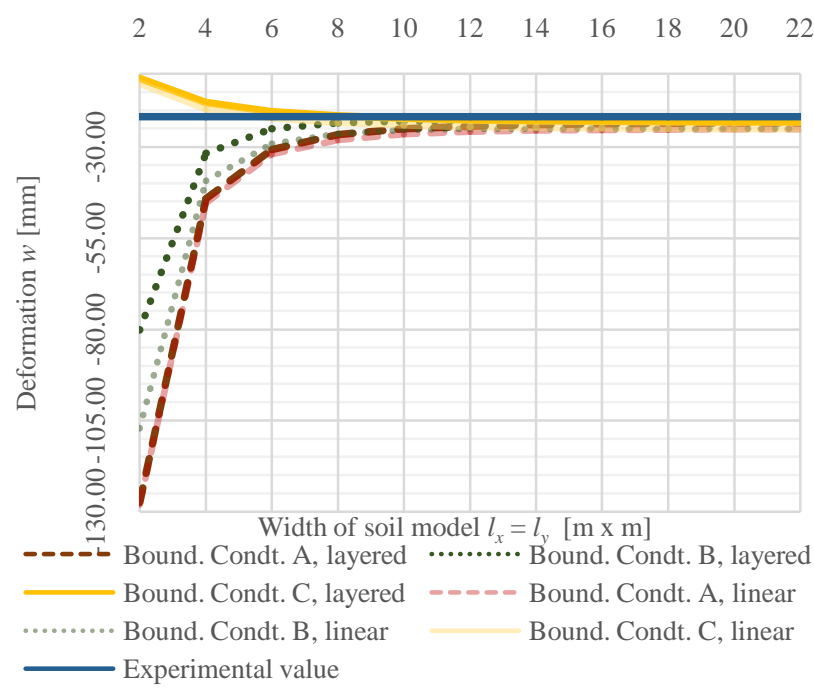

Fig. 14 - Surface deformation $w$ for layered cube model variant 2 with different width of the cube $l_{x}=$ ly for linear cube model with height $l_{z}=10$ meters from Table 3 in all three boundary conditions, homogeneous cube model variant 2 (Figure 12) in all three boundary conditions (Figure 5) and experimentally measured deformation. Author: Z.N.

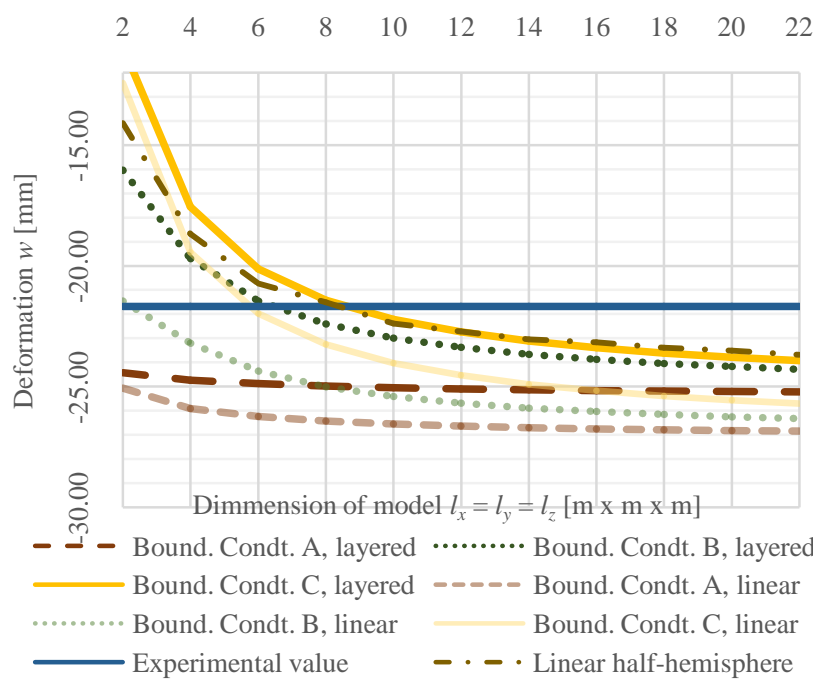

Fig. 15 - Surface deformation $w$ for layered cube model variant 3 with different height of the cube $l_{z}$ which is same as width $l_{x}=l_{y}$ from Table IV in all three boundary conditions, cube model variant 3 homogeneous (Figure 12) in all three boundary conditions (Figure 5), linear half-sphere from Table
5 and experimentally measured deformation. Author: Z.N.

\section{Discussion}

This article was executed as an extension and a subsequent research to the research from Luabudkova and Cajka [13] which was limited by the calculation time and a model size, because the whole research was performed on the table computer. This research brings in larger model size options as well as another model options (halfsphere model). This larger research introduces important data showing the direction of the deformation graph. The dependence of the deformation to the size model is finally clearly described, which was unknown in previous research precisely due to the limitation of the model size.

When examining the graphs (Figure 13, Figure 14, and Figure 15), the numerical model results vary from the experimental result. We get the closest results from the cube models with a height set to $10 \mathrm{~m}$ and variable width (Figure 13). The problem with this solution is that it will give us different results if we set the height to $20 \mathrm{~m}$ instead. But the height of $5 \times$ slab size works well in this case.

If we compare this new revelation to the other two graphs (Figure 13, Figure 14, and Figure 15), we will find some other models that represent experimental value pretty close at the model size of $10 \mathrm{~m}$. Figure 12 shows a half-sphere model and layered cube with $\mathrm{C}$ boundary conditions. Both models intersect the experimental value roughly at 9 meters which is $4.5 \times \mathrm{b}$ (slab width). Figure 14 shows the closest results to experimental values same numerical models followed by the layered cube model with B boundary conditions. Other models result in larger deformation.

The standard CSN 731001 defines the affected depth and affected width of the subsoil as $2 \times b$ for the depth and $6 \times b$ for width. This recommended depth $(4 \mathrm{~m})$ is significantly smaller than our resulted depth from the parametric study $(9 \mathrm{~m})$. This recommended depth can be used only for special cases. Linear cube models with boundary conditions type A and B and layered cube model with boundary conditions type A would work the best using recommended depth $4 \mathrm{~m}$.

As mentioned before, similar parametric study was made before [2], but the results were not clear due to the size area of the model. The study was limited by the calculation time requirements. Due to this limitation study stops at dimensions of cube 8 m. Also, the amount of produced models was limited concerning the effort and time required. It 
can be said that this process was inefficient and the exploring area was not large enough to answer all questions. The biggest issue was the insufficient amount of models. After comparison, the deformation values with increasing dimensions cannot be predicted.

This study eliminates the lack of variability of previous work [2] on dimensions of the model and understanding of the influence of selected boundary conditions on them. Although selected models are not sophisticated enough and do not take real behavior into account well, the maximum simplification of the task contributes to the clarification and separation of individual influences. Now the influence of the model dimensions and the boundary conditions is clarified, and in future works, the detected influences can be taken into account when evaluating the results.

\section{Conclusion}

This parametric study was computed by Anselm supercomputer using 4 nodes by 16 cores. The largest task has 10.12 million degrees of freedom and the calculation lasts 14 minutes. This task is unsolvable on a standard workstation due to the number of unknowns which results from the intention to keep the finite element size the same for all models.

The half-sphere model with a radius of $10 \mathrm{~m}$ and layered cube model with bottom and sides pinned shows results overall closest to the experimental value. The optimal model depth was evaluated as 9 meters for these cases, which means $4.5 \times b$ of the slab.

Recommendation from the standard CSN 731001 defines affected depth as $2 \times b$ of the slab which doesn't correspond with the depth evaluated from the parametric study; therefore it can be used only in special cases.

The following phenomena were detected in comparison to the linear elastic half-space:

The slopes of the curves are different in the homogeneous and layered model;

The behavior of the cube model is not the same for the homogeneous and layered model. In the homogeneous cube model, the slope of the curve stabilizes and the deformation increases linearly with increasing size. In the layered cube model, the deformation grows non-linearly;

The deformation increases with the depth of the modeled area in every case, but the increment in the case of layered half-space is stiffer; the half-sphere model stiffness is comparable with the layered cube model pinned on the bottom and sides.
The most significant changes between the homogeneous and layered model are in the boundary conditions type B - pinned at the bottom with supported sizes where the vertical displacement is allowed.

Based on this observation we can clearly state that computed deformation depends on the following influences:

- $\quad$ Boundary conditions;

- $\quad$ Selected material model;

- $\quad$ The dimension of modeled subsoil;

- Width to height ratio of modeled subsoil.

For future research, it is important to apply all the partial results on a case on a larger scale. Numerical results are hard to compare to reality because the real structures are not closely measured. Therefore, we plan to build in the measuring systems during the building a real construction and measure the tension with under-soil and compare these results with a numerical model. The numerical model of such a size will need to be computed on a supercomputer since the table computer is insufficient. Research introduced in this paper will help us to keep the supercomputing fast and optimal. This planned method will allow us to prove and debug the numerical method and use it for the construction of buildings in the civil engineering practice.

\section{Acknowledgments}

This work was supported by the Student Grant Competition held at Faculty of Civil Engineering, Technical University of Ostrava under Grant No. SP2020/82 "Nonlinear model of concrete slab-soil interaction using the supercomputer"; The Ministry of Education, Youth and Sports from the Large Infrastructures for Research, Experimental Development and Innovations under Grant „IT4Innovations National Supercomputing Center LM2015070“ and Moravian-Silesian Region under Grant "Support of Science and Research in the Moravia-Silesia Region 2017” (RRC/10/2017).

References:

[1] M. Ibrahim, I.M. Metwally, Three-dimensional finite element analysis of reinforced concrete slabs strengthened. 2014. Advances in Concrete Construction. 2014, Vol. 2(No. 2):91-108 
[2] R. Cajka, J. Labudkova, Dependence of deformation of a plate on the subsoil in relation to the parameters of the 3D model, International Journal of Mechanic. 2014, pp. 208-215. Retrieved from http://www.naun.org/main/NAUN/mechanics/2 014/a342003-076.pdf

[3] F. Kolarik, B. Patzak, L.N. Thrane, Modeling of fiber orientation in viscous fluid flow with application to self-compacting concrete. COMPUTERS \& STRUCTURES. 2015, 154. 91-100.

https://doi.org/10.1016/j.compstruc.2015.03.00 7

[4] M.G. Kotsovou, E. Vougioukas, Assessment of design methods for punching through numerical experiments, Computers and Concrete. 2016, 17(3). https://doi.org/10.12989/cac.2016.17.3.305

[5] J. Kralik, P. Rosko, J. Kralik, Effectiveness of Probabilistic Methods to Analyse Probability of Structural Failure Using ANSYS Software. International Conference of Numerical Analysis and Applied Mathematics (ICNAAM 2017). 2018, 978. https://doi.org/10.1063/1.5043808

[6] O. Axelsson, M. Neytcheva, Z.Z. Liang, Parallel Solution Methods and Preconditioners for Evolution Equations. i. 2018, 23(2). 287308. https://doi.org/10.3846/mma.2018.018

[7] F. Gorgeri, Composition of Permanences in Urban Landscape. Plan for Saint-Die 1945-46. Journal of Architecture and Urbanism. 2016, $40 \quad$ (2). 143-150. https://doi.org/10.3846/20297955.2016.118353 0

[8] E.N. Ekhaese, B. Amole, B., O. Izobo-Martins, Prefiguring Houses in a Traditional City: A Case For Benin House Types and Characteristics. Journal of Architecture and Urbanism. 2018, 42(1). 1-15. https://doi.org/10.3846/20297955.2014.994810

[9] A. Riekstins, Teaching Parametricism as a Standard Skill for Architecture. Journal of Architecture and Urbanism. 2018, 42(1). 3439. https://doi.org/10.3846/jau.2018.1476

[10] M. Aboutalebi, A. Alani, J. Rizzuto, D. Beckett, Structural behaviour and deformation patterns in loaded plain concrete groundsupported slabs, Structural Concrete. 2014, 15(1),

81-93. https://doi.org/10.1002/suco.201300043

[11] R. Cajka, V. Krivy, D. Sekanina, Design and Development of a Testing Device for
Experimental Measurements of Foundation Slabs on the Subsoil. Transactions of the VSB Technical University of Ostrava, Civil Engineering Series. 2011, 11 (1), 1-5. https://doi.org/10.2478/v10160-011-0002-2

[12] R. Cajka, Comparison of the calculated and experimentally measured values of settlement and stress state of concrete slab on subsoil, Applied Mechanics and Materials. 2014, 501504, 867-876. https://doi.org/10.4028/www.scientific.net/AM M.501-504.867

[13] R. Cajka, J. Labudkova, P. Mynarcik, Numerical solution of soil - foundation interaction and comparison of results with experimental measurements, International Journal of GEOMATE, 2016, 11(1), 21162122. Retrieved from http://www.geomatejournal.com/sites/default/fi les/articles/2116-2122-1208-lobudkova-July2016-c1.pdf

[14] J. Halvonik, L. Majtanova, Experimental Investigation of the Maximum Punching Resistance of Slab-Column Connections, Slovak Journal of Civil Engineering, 2018, 26(3), 22-28. DOI: 10.2478/sjce-2018-0017

[15] D. Kueres, M. Ricker, J. Hegger, Improved Shear Reinforcement for Footings-Maximum Punching Strength. ACI Structural Journal. 2018, 115(5). 1365-1377. https://doi.org/10.14359/51702374

[16] E. Hrubesova, M. Mohyla, H. Lahuta, T.Q. Bui, P.D. Nguyen, Experimental analysis of stresses in subsoil below a rectangular fiber concrete slab. Sustainability (Switzerland.). 2018 10 https://doi.org/10.3390/su10072216

[17] D. Tomasovicova, N. Jendzelovsky, Stiffness Analysis of the Subsoil under Industrial Floor. 3rd International Conference on Structural and Physical Aspects of Construction Engineering (SPACE). 2017, 190, 365-370. https://doi.org/10.1016/j.proeng.2017.05.350

[18] A. Meskenas, V. Gribniak, G. Kaklauskas, A. Sokolov, E. Gudonis, A. Rimkus, Experimental Investigation of Cracking Behaviour of Concrete Beams Reinforced with Steel Fibres Produced in Lithuania. Baltic Journal of Road and Bridge Engineering. 2017, 12(2). 82-87. https://doi.org/10.3846/bjrbe.2017.10

[19] J. Wawrzenczyk, A. Molendowska, A. Klak, Frost Durability of Steel Fiber SelfCompacting Concrete for Pavements. Baltic Journal of Road And Bridge Engineering. 
2016 ,

11(1).

35-42.

https://doi.org/10.3846/bjrbe.2016.04

[20] J. Vašková, Application of 3D Finite Elements for Determination of Subsoil-Structure Interaction [online]. Ostrava, 2017 [cit. 201905-23]. Retrieved from: http://hdl.handle.net/10084/120138

[21] Z. Neuwirthová, R. Cajka, Parametric Study of Input Parameters of Soil-Structure Interaction based on Elastic Half-Space Theory, WSEAS Transactions on Applied and Theoretical Mechanics. 2018, 13,18,167-174. Retrieved from

http://www.wseas.org/multimedia/journals/mec hanics/2018/a365111-352.pdf

[22] P. Kohnke, ed. ANSYS Theory Reference. Release 15.0. U.S.A.: SAS IP. 2013

[23] J. Feda, Z.P. Bazant, Stress in subsoil and methods of final settlement calculation. New York: distribution for the U.S.A. and Canada, Elsevier/North Holland. 1978. ISBN 04-4499800-4. 